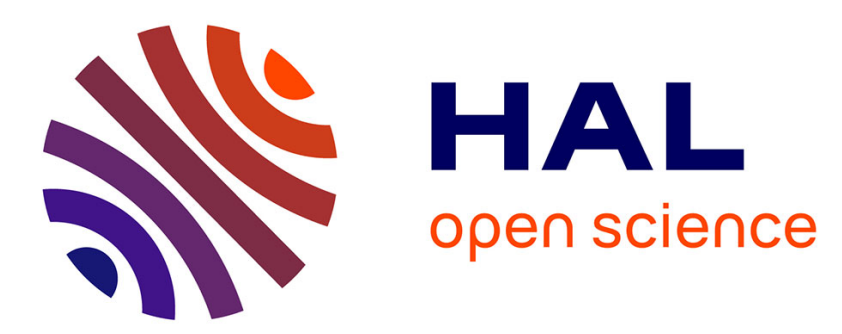

\title{
Organisation of clay nanoplatelets in a polyelectrolyte-based hydrogel
}

Claire Hotton, Juliette Sirieix-Plénet, Guylaine Ducouret, Thomas Bizien, Alexis Chennevière, Lionel Porcar, Laurent Michot, Natalie Malikova

\section{To cite this version:}

Claire Hotton, Juliette Sirieix-Plénet, Guylaine Ducouret, Thomas Bizien, Alexis Chennevière, et al.. Organisation of clay nanoplatelets in a polyelectrolyte-based hydrogel. Journal of Colloid and Interface Science, 2021, 604, pp.358-367. 10.1016/j.jcis.2021.07.010 . hal-03342976

\section{HAL Id: hal-03342976 https://hal-espci.archives-ouvertes.fr/hal-03342976}

Submitted on 27 Sep 2021

HAL is a multi-disciplinary open access archive for the deposit and dissemination of scientific research documents, whether they are published or not. The documents may come from teaching and research institutions in France or abroad, or from public or private research centers.
L'archive ouverte pluridisciplinaire HAL, est destinée au dépôt et à la diffusion de documents scientifiques de niveau recherche, publiés ou non, émanant des établissements d'enseignement et de recherche français ou étrangers, des laboratoires publics ou privés. 


\title{
Organisation of clay nanoplatelets in a polyelectrolyte-based hydrogel
}

\author{
Claire Hotton ${ }^{\mathrm{a}, *}$, Juliette Sirieix-Plénet ${ }^{\mathrm{a}}$, Guylaine Ducouret ${ }^{\mathrm{b}}$, Thomas Bizien ${ }^{\mathrm{c}}$, Alexis Chennevière ${ }^{\mathrm{d}}$, Lionel Porcar , $^{\mathrm{e}}$ \\ Laurent Michot $^{\mathrm{a}}$, Natalie Malikova ${ }^{\mathrm{a}, *}$ \\ ${ }^{a}$ Laboratory of Physical Chemistry of Electrolytes and Interfacial Nanosystems (PHENIX), Sorbonne Université, CNRS, 75005 Paris, \\ France \\ ${ }^{b}$ Laboratory of Soft Matter Sciences and Engineering (SIMM), ESPCI Paris, PSL Research University, CNRS, F-75005 Paris, France \\ ${ }^{c}$ Synchrotron SOLEIL, l'Orme des Merisiers, Saint-Aubin - BP 48, 91192 Gif-sur-Yvette CEDEX, France \\ ${ }^{d}$ Laboratoire Leon Brillouin, UMR12 CEA-CNRS-Université Paris-Saclay, Gif sur Yvette, F-91191, France \\ ${ }^{e}$ Large Scale Structures, Institut Laue Langevin, Grenoble F-38042, France
}

\begin{abstract}
We investigate the organisation of clay nanoplatelets within a hydrogel based on modified ionenes, cationic polyelectrolytes forming physically crosslinked hydrogels induced by hydrogen bonding and $\pi$ - $\pi$ stacking. Combination of small angle X-ray and neutron scattering (SAXS, SANS) reveals the structure of the polyelectrolyte network as well as the organisation of the clay additives. The clay-free hydrogel network features a characteristic mesh-size between 20 to $30 \mathrm{~nm}$, depending on the polyelectrolyte concentration. Clay nanoplatelets inside the hydrogel organise in a regular face-to-face stacking manner, with a large repeat distance, following rather closely the hydrogel mesh-size. The presence of the nanoplatelets does not modify the hydrogel mesh size. Further, the clay-compensating counterions $\left(\mathrm{Na}^{+}, \mathrm{Ca}^{2+}\right.$ or $\mathrm{La}^{3+}$ ) and the clay type (montmorillonite, beidellite) both have a significant influence on nanoplatelet organisation. The degree of nanoplatelet ordering in the hydrogel is very sensitive to the negative charge location on the clay platelet (different for each clay type). Increased nanoplatelet ordering leads to an improvement of the elastic properties of the hydrogel. On the contrary, the presence of dense clay aggregates (tactoids), induced by multi-valent clay counterions, destroys the hydrogel network as seen by the reduction of the elastic modulus of the hydrogel.
\end{abstract}

Keywords: Hydrogel, clay, polyelectrolyte, ionene, SAXS, SANS

\section{Introduction}

Hydrogels have attracted a lot of attention due to their numerous applications especially in the biomedical field where they provide the basis for stimuli-responsive arti5 ficial tissues, for vehicles in drug delivery or for biosensors [1, 2, 3, 4]. The combination of hydrogels and colloidal dispersions opens an even wider window of potential applications [5, 6]. More specifically, association of clay nanoparticles and hydrogels has a great potential in 10 the design of materials that exhibit additional mechanical, optical, swelling or barrier properties [7]. Smectites, especially montmorillonite and laponite, a synthetic hectorite, are the most widely used clay additives 8 . Smectites are layered aluminosilicates that exhibit a negative 15 charge on the surface coming from partial isomorphous substitutions in the crystalline structure [9]. The charge is neutralised by alkali and alkaline earth cations, which become mobile with an increasing water content of the system. This leads to high cation exchangeability, absorption, and swelling properties of clay minerals [7]. Further, clay

\footnotetext{
* Corresponding author

Email addresses: claire.hotton@sorbonne-universite.fr (Claire Hotton), natalie.malikova@sorbonne-universite.fr (Natalie Malikova)
}

particles are highly anisotropic (plate-like shape), which leads to a much richer set of possible organisations inside the gel.

The use of a polyelectrolyte compared to a neutral polymer to form nanocomposite hydrogels, leads to a richer set of possible interactions due to the introduction of electrostatics forces in addition to hydrogen bonding, hydrophobic interactions and van der Waals forces $[8$. Moreover, the influence of local effects, such as ion-specificity or exact charge locations on the interactions between the clay particles and the polyelectrolyte chains can be critical. These interactions thus determine the structure of claypolyelectrolyte based hydrogels. The polyelectrolytes can wrap around clay platelets, be intercalated inside clay layers, induce flocculation or exfoliation of the platelets [10, 11, 12. A set of key parameters influences this structure including the molecular weight [13, 14, the chain-charge density and the concentration of the polyelectrolyte [15]; the size [16], the clay concentration [7], and the type [17. of the clay platelets. Nonetheless the set of requirements to obtain one or another structure remains unclear. The need to estimate quantitatively the degree of intercalation and exfoliation in such systems is still challenging in order to establish the link between structure and mechani45 cal, swelling or barrier properties [18. Moreover, most of 


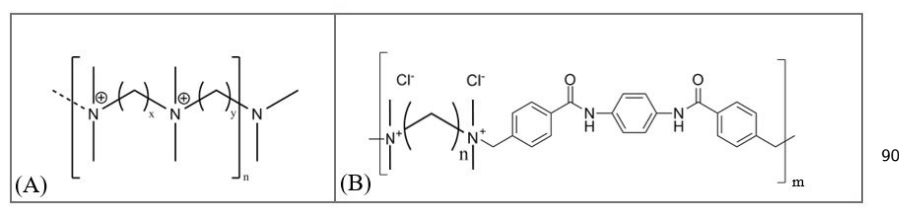

Figure 1: (A) Structure of a classical ionene polymer, $\mathrm{x}$ and $\mathrm{y}$ represented the number of methylene groups separating the charged quaternary ammonium centers. Charges are compensated by $\mathrm{Br}^{-}$ counterions. (B) Structure of an $\mathrm{n}-\mathrm{Cl}$ modified ionene, $\mathrm{n}$ represents the number of methylene groups separating the charged quaternary 95 ammonium centers. In this paper $n$ is fixed at $n=6$. Charges are compensated by $\mathrm{Cl}^{-}$counterions.

these studies have been done with anionic polyelectrolytes100 or neutral polymers and only a few relate to cationic polyelectrolytes 19, 20.

In the current study, we are concerned with a physically cross-linked hydrogel formed with a cationic polyelectrolyte, a modified ionene, and different smectite clays (Arizona montmorillonite, Wyoming montmorillonite and $_{105}$ beidellite) of specific size fractions and counterions as additives. Ionenes 21 are cationic polyelectrolytes composed of charged ammonium quaternary centres on the main chain and separated by methylene groups, Figure 1 (A). Ionenes are strong polyelectrolytes, which means ${ }_{110}$ that the charge is $\mathrm{pH}$ independent, and their charge density is not statistical, but regular and tuneable by synthesis. Therefore, they are considered as model cationic polyelectrolytes and they have been used in several studies related to antimicrobial agents [22, humidity detec- ${ }_{115}$ tors 23] or ion-exchange resins [24]. While conventional ionenes do not form gels, introducing linkers with benzene and amide moieties into the ionene backbone opens the possibility of hydrogelation, where the $\pi-\pi$ interactions between benzene groups and the hydrogen bonding between $n_{120}$ amide groups provide the necessary chain crosslinking [25] 26. The modified ionene structure is presented in Figure 1 (B). An aqueous solution of the modified ionene needs a thermal treatment to induce gelation. While gelation of modified ionenes has been reported previously 26, the structural changes in the polyelectrolyte network taking ${ }_{125}$ place during the gelation process are shown here for the 75 first time.

Ionenes have already proved their ability to act as a flocculating agent for clay suspensions in a liquid state 27, 15. Introduction of benzene and amide moieties into ${ }_{130}$ the ionene backbone can lead to several possible interac-

so tions with clay. In this paper, we will focus on a single chain charge density for the modified ionene. The $6-\mathrm{Cl}$ modified ionene (6- $\mathrm{Cl}$ mod ionene) is chosen as it displays the best gelation ability [26. We follow here the ${ }_{135}$ structural changes in the polyelectrolyte network on gel

85 formation and give an experimental evidence of the $\pi-\pi$ interactions. Then, the focus turns towards the study of clay nanoplatelet organisation throughout the process of gelation and in the final 6-Cl mod ionene based hydrogel. The 6-Cl mod ionene/clay based hydrogel is studied here at the nanoscale by means of small angle X-Ray scattering (SAXS) and small angle neutron scattering (SANS). We concentrate on the influence of the clay volume fraction, the clay type and clay-compensating counterions on the hydrogel structure as well as its rheological properties.

\section{Experimental section}

\subsection{6 - $C l$ mod ionene and precursor synthesis}

The 6-Cl mod ionene and its precursors were synthesized via a two-step reaction with a protocol adapted from the one described previously [26]. All chemical reagents were purchased from Sigma-Aldrich and used without further purification. All solvents were purchased from SigmaAldrich and VWR.

\subsubsection{First step: synthesis of 1,4-bis-[4-(chloromethyl)ben- zamidojbenzene}

All vials used were dried in a oven at $80^{\circ} \mathrm{C}$ the day before. $p$-phenylenediamine $(1.08 \mathrm{~g}, 10 \mathrm{mmol}, 1 \mathrm{eq})$ was dissolved in freshly distilled dichloromethane $(100 \mathrm{~mL})$ into a $250 \mathrm{~mL}$ round-bottom flask with a magnetic stirrer and placed under an inert argon atmosphere. The solution in the round-bottom flask was then cooled to $0^{\circ} \mathrm{C}$ by using an ice-water bath and triethylamine (3.5 mL, $25 \mathrm{mmol}, 2.5 \mathrm{eq})$ was added. A solution of 4-(chloromethyl)benzoyl chloride (3.78 g, $20 \mathrm{mmol}, 2 \mathrm{eq})$ dissolved in distilled dichloromethane $(70 \mathrm{~mL})$ was added dropwise with an isobar dropping funnel. After the addition, the ice-water bath was removed, and the system was warmed up to room temperature. The system was stirred for $24 \mathrm{~h}$ to ensure complete conversion. The obtained white precipitate was vacuum filtrated and then washed with distilled water $(2 \times 80 \mathrm{~mL})$. The product was dried under vacuum at $90^{\circ} \mathrm{C}$. The product was obtained in high yield (85\%). Structural analysis was carried out by ${ }^{1} \mathrm{H}-\mathrm{NMR}$ in DMSO- $\mathrm{d}_{6}$.

\subsubsection{Second step: synthesis of 6 - $\mathrm{Cl}$ mod ionene}

1,4-bis-[4-(chloromethyl)benzamido]benzene (2.06 g, 5 $\mathrm{mmol})$ was dissolved in dimethylformamide $(200 \mathrm{~mL})$ at $80^{\circ} \mathrm{C}$ in a $500 \mathrm{~mL}$ round-bottom flask with a magnetic stirrer. Then, N,N,N',N'-tetramethyl-1,6-hexanediamine $(1.07 \mathrm{~mL}, 5 \mathrm{mmol})$ was added. The system was stirred at $80^{\circ} \mathrm{C}$ for $48 \mathrm{~h}$. The obtained yellow precipitate was vacuum filtrated and washed subsequently with dimethylformamide $(100 \mathrm{~mL})$, acetonitrile $(100 \mathrm{~mL})$ and dichloromethane $(100 \mathrm{~mL})$. The product was dried under vacuum at $50^{\circ} \mathrm{C}$. The 6 - $\mathrm{Cl} \bmod$ ionene was obtained in good yield (75\%). Structural analysis was carried out by ${ }^{1} \mathrm{H}-\mathrm{NMR}$ in $\mathrm{D}_{2} \mathrm{O}$. The average molecular weight of the $6-\mathrm{Cl} \bmod$ ionene was previously determined as $7.8410^{4} \mathrm{Da}$ [26]. 


\subsection{Clay fraction, purification and cations exchange}

Three different clay minerals (two Na-montmorillonites, Arizona (SAz-1) and Wyoming (SWy-2), and a Na-beidellite from Idaho (SBId)) were purchased from the Source Claysıo Minerals Repository of the Clay Mineral Society at Purdue University, Indiana. Clay suspensions were purified and separated in size fractions by successive centrifugation following the previously established procedure [28, 29].

${ }_{145}$ Each fraction has a defined average platelet size with a185 reduced size polydispersity. Here we used one size fraction of Wyoming montmorillonite and Beidellite platelets (denoted T3) and three size fractions of Arizona montmorillonite (denoted T2, T3 and T4). The characteristic sizes and charge densities of the clay particles we are interested ${ }_{190}$ in are summarized in Table 1 .

Table 1: Main features of different clay particles used in this study: the lateral dimension $\mathrm{D}$, the polydispersity in diameter, the average thickness e and the cation-exchange capacity (CEC).

\begin{tabular}{|c|c|c|c|c|c|}
\hline & \multicolumn{3}{|c|}{ Saz-1 } & SWy-2 & SBId \\
\hline & T2 & T3 & $\mathrm{T} 4$ & T3 & T3 \\
\hline $\mathrm{D}(\mathrm{nm})$ & 150 & 95 & 60 & 100 & 209 \\
\hline $\begin{array}{l}\text { Polydispersity } \\
(\%)\end{array}$ & 42 & 19 & - & 25 & 38 \\
\hline e $(n m)$ & 0.7 & 0.7 & - & 0.7 & 1 \\
\hline $\begin{array}{l}\text { CEC } \\
(\mathrm{mmol} / 100 \mathrm{~g})\end{array}$ & 124.8 & 122.5 & 124.6 & 96.4 & 94.3 \\
\hline
\end{tabular}

Counterion exchange of the SAz1-T3-Na suspension was carried out with aqueous solutions of $\mathrm{La}\left(\mathrm{NO}_{3}\right)_{3}$ and $\mathrm{CaCl}_{2}$ at $0.1 \mathrm{M}$ and $0.5 \mathrm{M}$ respectively. The salt solutions were added to the clay suspension and the mixtures were stirred for $24 \mathrm{~h}$. The mixtures were then centrifuged $\mathrm{at}^{200}$ $7000 \mathrm{rpm}$ for 15 minutes. The supernatant was removed and the flocculent was re-dispersed in salt solutions. These steps were repeated three times. The final suspensions were washed ten times against ultrapure water.

\subsection{Preparation of the 6-Cl mod ionene/clay hydrogels}

The 6-Cl mod ionene gel without clay were formed by heating the ionene solution at $70^{\circ} \mathrm{C}$ for 10 minutes followed by cooling to room temperature. The critical gelation concentration (CGC) was determined to be around $10 \mathrm{~g} / \mathrm{L}$ via vial inversion method and rheology measurements. Regarding the formation of the 6-Cl mod ionene gel with clay, the 6-Cl mod ionene was first added into a clay suspension and dispersed by using a sonicator (Fisher Scientific FB 15051) for 15 minutes. Then the mixture was heated at $70^{\circ} \mathrm{C}$ for 10 minutes followed by cooling to room temperature to form the hydrogel (see pictures of the hydrogels on Supplementary Material S1). The sonication step was seen as essential for producing visually transparent gels. The CGC remains unchanged by the addition of clay.

\subsection{Small Angle X-ray Scattering (SAXS)}

SAXS experiments were conducted at the SWING beamline of the SOLEIL synchrotron (Orsay, France) using a fixed energy of $16 \mathrm{keV}$ with two samples-to-detector distances of $0.5 \mathrm{~m}$ and $6 \mathrm{~m}$. Thus the q range available, $\mathrm{q}$ being the diffusion vector, is $0.002 \AA^{-1}<\mathrm{q}<2 \AA^{-1}$. Cylindrical glass capillaries of $1 \mathrm{~mm}$ diameter were filled with the sample in solution state $\left(\right.$ at $\left.70^{\circ} \mathrm{C}\right)$ and flame sealed. The hydrogels are then formed inside the capillaries by cooling down to room temperature. Two-dimensional scattering patterns were recorded on an Eiger 4M (Dectris) detector. The values of the scattering length density and the contrast of the main components of the system are presented in Table 2. The size of the symbols of the SAXS curves reflects the errors bars.

Table 2: Values of the scattering length density (SLD) and contrast $\left(\Delta \rho^{2}\right)$ of the main components of the system for SAXS.

\begin{tabular}{|c|c|c|}
\hline & $6-C l$ mod ionene & SAz1-T3-Na \\
\hline X-ray SLD $\left(\mathrm{cm}^{-2}\right)$ & $6.910^{10}$ & $2.1210^{11}$ \\
\hline$\Delta \rho^{2}\left(\mathrm{~cm}^{-4}\right)$ with $\mathrm{H}_{2} \mathrm{O}$ & $6.3310^{20}$ & $1.8210^{22}$ \\
\hline
\end{tabular}

\subsection{Small Angle Neutron Scattering (SANS)}

SANS experiments under the condition of full contrast (in $\mathrm{D}_{2} \mathrm{O}$ solvent) were conducted at the Laboratoire Léon Brillouin (LLB) in CEA Saclay (France) on the PAXY facility. Three different sample-to-detector distances of 1 , 3 and $5 \mathrm{~m}$ were used together with a neutron wavelength of 4,5 and $8.5 \AA$ respectively. The q range available was thus $0.006 \AA^{-1}<\mathrm{q}<0.6 \AA^{-1}$. SANS measurements were carried out with samples inside quartz cells of path length of $2 \mathrm{~mm}$. The values of the scattering length density and the contrast of the main components of the system are presented in Table 3. SANS measurements performed under the contrast matching condition (in $\mathrm{H}_{2} \mathrm{O} / \mathrm{D}_{2} \mathrm{O}$ solvent mixture) for clay platelets were conducted at the Institute Laue-Langevin (ILL) in Grenoble (France) on the D22 spectrometer. Two different sample-to-detector distances of 3 and $17 \mathrm{~m}$ were used. The $\mathrm{q}$ range available was thus $0.002 \AA^{-1}<\mathrm{q}<0.6 \AA^{-1}$. SANS measurements were carried out with samples inside quartz cells of path length of $1 \mathrm{~mm}$.

Table 3: Values of the scattering length density (SLD) and of the contrast $\left(\Delta \rho^{2}\right)$ of the main components of the system for SANS.

\begin{tabular}{|c|c|c|}
\hline & 6 -Cl mod ionene & SAz1-T3-Na \\
\hline Neutron SLD $\left(\mathrm{cm}^{-2}\right)$ & $1.3310^{10}$ & $3.610^{10}$ \\
\hline$\Delta \rho^{2}\left(\mathrm{~cm}^{-4}\right)$ with $\mathrm{D}_{2} \mathrm{O}$ & $2.5110^{21}$ & $6.0610^{20}$ \\
\hline
\end{tabular}

\subsection{Rheology}

Rheology measurements were carried out on a straincontrolled rheometer, ARES TA instruments (LS1) equipped with a cone-plate geometry of $20 \mathrm{~mm}$ in diameter, an angle of $0.04 \mathrm{rad}$ and a gap of $0.043 \mathrm{~mm}$ at $25^{\circ} \mathrm{C}$. The frequency 
sweeps were performed in the linear viscoelastic regime at $1 \%$ in strain in a pulsation range from 1 to $100 \mathrm{rad} / \mathrm{s}$. The samples were introduced into the geometry one day after the gel formation. The duration of the measurement is less than the sample drying time. Each measurement was repeated twice to ensure reproducibility.

\subsection{UV-visible absorption spectroscopy}

UV-vis spectroscopy measurements were performed using a UVIKON XL Secoman UV spectrometer. The samples were subjected to photon radiation with a wavelength range between $180 \mathrm{~nm}$ and $900 \mathrm{~nm}$. The samples are placed between two quartz plates separated by $0.1 \mathrm{~mm}$.

\section{Results and discussion}

\subsection{Formation of the modified ionene based gel}

To have a complete overview of the system we investigate, we have first studied the formation and the structure of the 6-Cl mod ionene based gel without clay nanoplatelets. The gel formation consists in heating the ionene solution to $70^{\circ} \mathrm{C}$, a gel is formed after cooling back to room temperature. Heating to $70^{\circ} \mathrm{C}$ is an important step leading to good solubilisation of the $6-\mathrm{Cl}$ mod ionene chains. While classical ionenes are highly soluble in water and show the ${ }^{270}$ characteristics of hydrophilic chains across a wide range of charge densities [30, 31, the introduction of the benzene moieties into the ionene backbone makes the modified ionene chains partially hydrophobic. For this experiment, we used SANS measurements under conditions of ${ }^{275}$ full contrast (in $\mathrm{D}_{2} \mathrm{O}$ solvent) because the 6- $\mathrm{Cl}$ mod ionene polyelectrolyte have a very good contrast with deuterated water (refer to Table 3). In Figure 2, we present the scattering intensity of the 6 - $\mathrm{Cl}$ mod ionene at both high temperature $\left(70^{\circ} \mathrm{C}\right)$ and room temperature, i.e., in solution ${ }^{280}$ and in the gel states.

In the solution state, we observe the presence of a shoulder resembling the signal of a polyelectrolyte peak from classical ionenes and other polyelectrolytes [30] in the high q region. The shoulder is not as sharp as the peak we usually observe for polyelectrolyte systems. On the other ${ }_{285}$ hand, the scattered intensity cannot be fully described by an Ornstein-Zernike (OZ) function which is the typical behaviour for uncharged polymer solutions 32. The shoulder can be fitted with a Lorentz peak function within the broad peak model, referring to strongly charged polyelec- ${ }_{290}$

$$
I(q)=\frac{I_{0}}{1+\left(\frac{\left(q-q^{*}\right)}{B}\right)^{2}}
$$

where $\mathrm{q}^{*}$ is the interchain correlation position and B the width of the peak. However, as the peak width is difficult to determined due to the upturn in the low-q region (usually interpreted as the presence of large-scale aggregates or heterogeneities in polyelectrolyte solutions [34]), 300

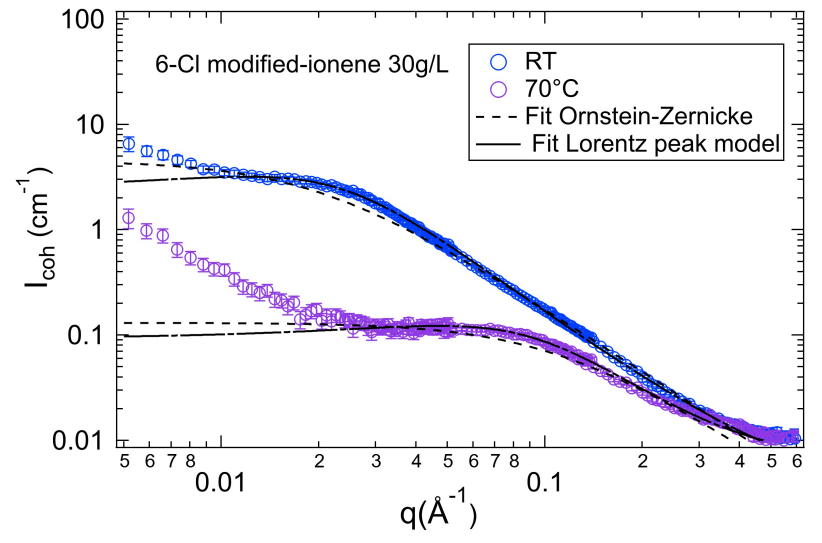

Figure 2: SANS profiles of $6-\mathrm{Cl} \bmod$ ionene at $30 \mathrm{~g} / \mathrm{L}$ at $70^{\circ} \mathrm{C}$ in solution state and at room temperature (RT) after gelation. The figure shows the coherent SANS intensity versus the wave vector $\mathrm{q}$ of the samples in $\mathrm{D}_{2} \mathrm{O}$.

$\mathrm{q}^{*}$ value is not best determined using the Lorentz peak model. Rather, we consider the value of the limit between the $\mathrm{q}^{-2}$ dependence of the curve in the middle q-region and the low-q region. Thus, the shoulder can be evaluated around $0.09 \AA^{-1}$. Previous studies on classical ionenes in aqueous solution have already shown a polyelectrolyte peak in this q-region for equivalent molar concentration in charge [31. The typical "mesh-size" $\xi=\frac{2 \pi}{q^{*}}$ of the chain network in solution is determined as $7 \mathrm{~nm}$.

It has been shown in previous studies 35. that the scattering intensity $I_{\text {tot }}(\mathrm{q})$ of polymer gels is the sum of a scattering function $I_{s}(\mathrm{q})$ due to thermal concentration fluctuations and corresponding to the scattering intensity of the polymer solution, and an excess scattering function $I_{d}(\mathrm{q})$ due to heterogeneities introduced by cross-linking:

$$
I_{t o t}(q)=I_{s}(q)+I_{d}(q)
$$

In the gel state, we observe in Figure 2 an additional shoulder in the low wave-vector region, around $0.03 \AA^{-1}$, correponding to the $I_{d}(\mathrm{q})$ contribution. This contribution is also best described with a Lorentz peak function. The formation of the gel is thus accompanied by the appearance of an additional larger characteristic mesh-size $\Xi$ estimated as $21 \mathrm{~nm}$. This additional mesh-size corresponds to the distance between physical cross-linking nodes of the hydrophobic groups in the 6-Cl mod ionene chains. Moreover, a slight upturn in $\mathrm{I}(\mathrm{q})$ at very low q region appears in the gel state. This upturn in $\mathrm{I}(\mathrm{q})$ is confirmed by the SAXS signal of the $6-\mathrm{Cl}$ mod ionene, where we can access to the scattered intensity for smaller q values (see the Supporting Information, Figure S2). This type of upturn in the small q-range is characteristic of the heterogeneities introduced by cross-linking. The shoulder corresponding to the $I_{s}(\mathrm{q})$ contribution is weakly visible around $0.1 \AA^{-1}$. Hence, in the long wave vector limit the scattering intensity can be 


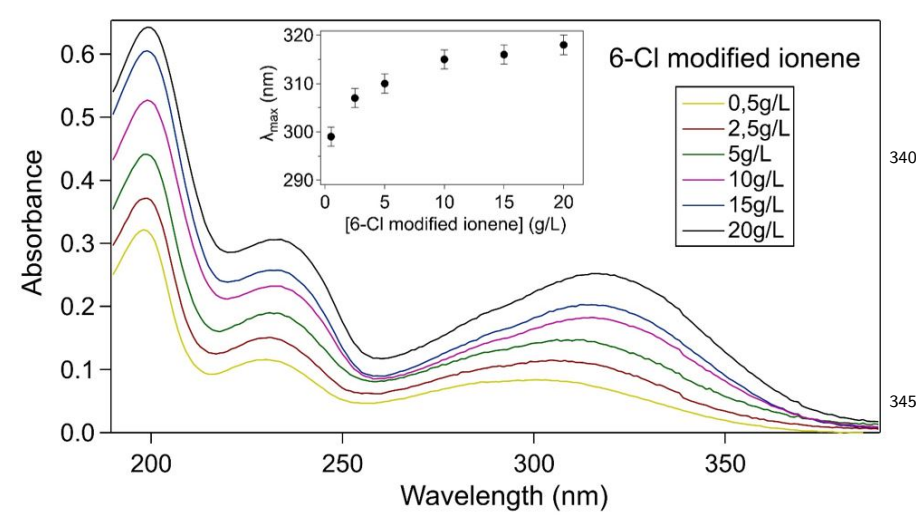

Figure 3: UV-visible measurements of $6-\mathrm{Cl}$ mod ionene in water ${ }_{350}$ at different concentrations. The inset features the evolution of the third absorption maximum as a function of the $6-\mathrm{Cl} \bmod$ ionene concentration.

reduced to the $I_{s}(\mathrm{q})$ contribution.

It has been evoked in the literature that the gel formation for ionene-based systems is possible thanks to hydrogen bonds and $\pi-\pi$ stacking [26, 25]. Hydrogen bonding between amide groups can be evidenced by FT-IR [26]. ${ }^{36}$ However, $\pi-\pi$ stacking interactions deserve further clear experimental evidence in this system. UV-visible absorption measurements have been made to follow the evolution of $\pi-\pi$ stacking interactions in the 6 - $\mathrm{Cl}$ mod ionene gel and solution. UV-visible absorption measurements are ${ }^{36}$ performed at different concentrations of 6 - $\mathrm{Cl}$ mod ionene before and after the critical gelation concentration (CGC). The absorbance represented in Figure 3 is not an absolute absorbance due to the difficulty to obtain a constant thickness between the quartz plates from one sample to ${ }^{37}$ another. From Figure 3, we note the presence of three absorption maximums corresponding to $\pi-\pi^{*}$ transitions. Two absorption maximums are observed at $199 \mathrm{~nm}$ and at $233 \mathrm{~nm}$ regardless of the concentration of $6-\mathrm{Cl} \bmod$ ionene which can be attributed respectively to the two $\mathrm{E}^{-375}$ bands (ethylenic). The third absorption maximum is between $299 \mathrm{~nm}$ and $318 \mathrm{~nm}$ and can be assigned to B-band (benzoic). Before the CGC at $10 \mathrm{~g} / \mathrm{L}$, the third absorption peak shifts towards higher wavelengths with increasing concentration of the $6-\mathrm{Cl} \bmod$ ionene. We therefore ${ }^{380}$ observe a bathochromic effect. Indeed, when $\pi-\pi$ stacking interactions occur in the system, the transition energy from the highest occupied $\pi$ orbital to the lowest unoccupied $\pi$ orbital decreases due to overlaps of the $\pi-\pi$ molecular orbitals of the aromatic groups. A decrease in the ${ }^{385}$ transition energy results in a shift of the $\lambda_{\max }$ of the absorption band towards higher wavelengths [36]. After the CGC, the wavelength at which we observed the third absorption peak remains constant. It has been suggested that the hydrogen bonding interaction between the amide ${ }^{390}$ groups could be made indirectly through $\mathrm{Cl}^{-}$counterions and water molecules 26. Thus, we could suggest that the presence of a shoulder instead of a sharp peak in the SANS signal may be due to the cross-linking attractive interactions as part of the charge could participate to this cross-linking. Moreover anion- $\pi\left(\mathrm{Cl}^{-}-\pi\right)$ interactions and cation- $\pi\left(\mathrm{N}^{+}-\pi\right)$ interactions could screen the electrostatic repulsion responsible of the polyelectrolyte peak.

\subsection{Effect of polymer concentration and clay volume frac- tion on 6-Cl mod ionene/clay hydrogels}

In SAXS experiments, the scattered intensity depends on the electron density of the materials analyzed. Thus, in our system, the scattered intensity is mostly due to clay nanoplatelets because of their higher X-ray scattering contrast in $\mathrm{H}_{2} \mathrm{O}$ compared to the one of $6-\mathrm{Cl}$ mod ionene (refer to Table 2). The SAXS experiment therefore makes it possible to study the organisation of clay platelets in the gel. Before describing our findings on the structure of the system, it is meaningful to recall some previous results regarding the components of our system. In very diluted clay suspensions, the scattering patterns present a monotonous decay of the scattering intensity that scales as a $\mathrm{q}^{-2}$ law. This is characteristic of the scattering from non-interacting disks in the intermediate regime where $\frac{2 \pi}{D}<\mathrm{q}<\frac{2 \pi}{e}, \mathrm{D}$ being the average lateral dimension of the disk and e the thickness 37. Thus, the $\mathrm{q}^{-2}$ law represents the form factor of the system and the $\mathrm{q}^{2} \mathrm{I}(\mathrm{q})$ representation can be plotted to emphasise the structural features superimposing onto the $\mathrm{q}^{-2}$ decay. For clay suspensions, depending on the volume fraction and the ionic strength, two major variations of the scattered intensity can be distinguished. The first one is the appearance of a periodic modulation in the middle-q region (from $0.005 \AA^{-1}$ to $0.1 \AA^{-1}$ ) due to long or short-range positional order of the platelets. The second one is the appearance of a peak in the high-q region corresponding to distances comparable to the thickness of one or several water layers and reflecting the interlamellar distance within dense face-to-face clay aggregates also called tactoids. In our study, the $\mathrm{q}^{2} \mathrm{I}(\mathrm{q})$ representation shall give access to the local organisation of the clay platelets within the hydrogel as variations in the scattering intensity inform us on characteristic distances within the system. The range of the clay volume fraction considered here is $\phi=0.07 \%$ to $\phi=0.38 \%$. At this volume fractions, pure clay suspensions of montmorillonite or beidellite are isotropic liquids 38 39. Figure 4 features the SAXS patterns of the 6-Cl mod ionene/SAz1-T3-Na hydrogels at a constant $6-\mathrm{Cl}$ mod ionene concentration and varying the clay volume fraction. In the gel state, i.e. when the 6$\mathrm{Cl}$ mod ionene concentration is higher than the CGC, the SAXS patterns are isotropic and exhibit a periodic modulation of the scattered intensity. This means that the addition of clay platelets into the 6 - $\mathrm{Cl}$ mod ionene network involves the emergence of a middle-range positional order of the platelets. The average interparticle distance $\bar{d}$ can be predicted from the positions of the maxima of these oscillations $q_{\max }, 2 q_{\max }, 3 q_{\max }$, etc, according to 
$\bar{d}=\frac{2 \pi}{q_{\max }}$. Surprisingly, the average interparticle distance is independent of the clay volume fraction. Indeed, at tance $\bar{d}$ is $18 \mathrm{~nm}$ whatever the clay volume fraction. This interparticle distance is much higher than the interlamellar distance of 1.43-1.46 nm in clay/ionene tactoids [15] and lower than if the platelets only experienced electrostatic or ume fractions of the same order of magnitude (around $\phi$ $=0.5 \%$ ) 38. Another important feature that we need to emphasize is the intensity upturn in the low q region. It is clearly visible in the $\mathrm{q}^{2} \mathrm{I}(\mathrm{q})$ representation. Such evolution suggests the presence of heterogeneities in the distribution of the platelets in the system. Indeed, at the same clay volume fraction, pure clay suspensions present a $q^{0}$ dependence in the low q region. Overall, the data suggests a strong face-to-face correlation indicating that platelets inside the hydrogel form stacked discs. These stacks have to be distinguished from tactoids by the interparticle distance which is significantly higher $(\sim 20 \mathrm{~nm}$ compared to $\sim 1.5 \mathrm{~nm}$ in tactoids) and by the fact that in this case, clay platelets are in the osmotic swelling region. It might 415 be of interest to confirm this organisation at larger scales using optical microscopy techniques.

Figure 5 (A) presents the SAXS signals of the 6-Cl mod ionene/SAz1-T3-Na gels at a constant clay volume fraction of $\phi=0.15 \%$ and at different 6 - $\mathrm{Cl}$ mod ionene concentra-

Interestingly, at a constant clay volume fraction, the structure of the hydrogel is different depending on the $6-\mathrm{Cl}$ mod ionene concentration. At the CGC, the results reveal that the clay platelets display less pronounced correlation peaks compared to higher $6-\mathrm{Cl} \bmod$ ionene conchtration. When the $6-\mathrm{Cl} \bmod$ ionene concentration is increased, the correlation peaks are shifted towards high $q$ regions meaning that the average interparticle distance $\bar{d}$ decreases from $27 \mathrm{~nm}$ to $16 \mathrm{~nm}$ for $10 \mathrm{~g} / \mathrm{L}$ to $40 \mathrm{~g} / \mathrm{L}$ of 6 - $\mathrm{Cl}$ mod ionene respectively. Overall, we observe that the $6-\mathrm{Cl}$ mod ionene concentration is the parameter that ${ }^{450}$ dictates the local platelet organisation in the system. The distance between clay platelets in a stack is thus mediated by the $6-\mathrm{Cl}$ mod ionene network. Figure 5 (B) shows the SANS curves of the $6-\mathrm{Cl} \bmod$ ionene pure hydrogel from $10 \mathrm{~g} / \mathrm{L}$ to $40 \mathrm{~g} / \mathrm{L}$ in ionene. In the pure hydrogel, we ob- ${ }^{45}$ served characteristic mesh sizes between the ionene chains very similar to distances between the clay particles, from $33 \mathrm{~nm}$ to $18 \mathrm{~nm}$ for $10 \mathrm{~g} / \mathrm{L}$ to $40 \mathrm{~g} / \mathrm{L}$ of $6-\mathrm{Cl} \bmod$ ionene respectively.

Figure 6 compares the evolution of (1) the mesh size s60 $^{460}$ between the $6-\mathrm{Cl}$ mod ionene chains in pure hydrogels, (2) the mesh size between the $6-\mathrm{Cl}$ mod ionene chains in hydrogel with clay additives and (3) the average interparticle distance of clay platelets as a function of the $6-\mathrm{Cl}$ mod ionene concentration for a fixed clay volume fraction ${ }^{465}$ of $\phi=0.15 \%$. We consider the SAXS (Figure S3) and the SANS scattering intensity of the $6-\mathrm{Cl} \bmod$ ionene in water at different concentrations. Even though the absolute intensities are different between SAXS and SANS due to
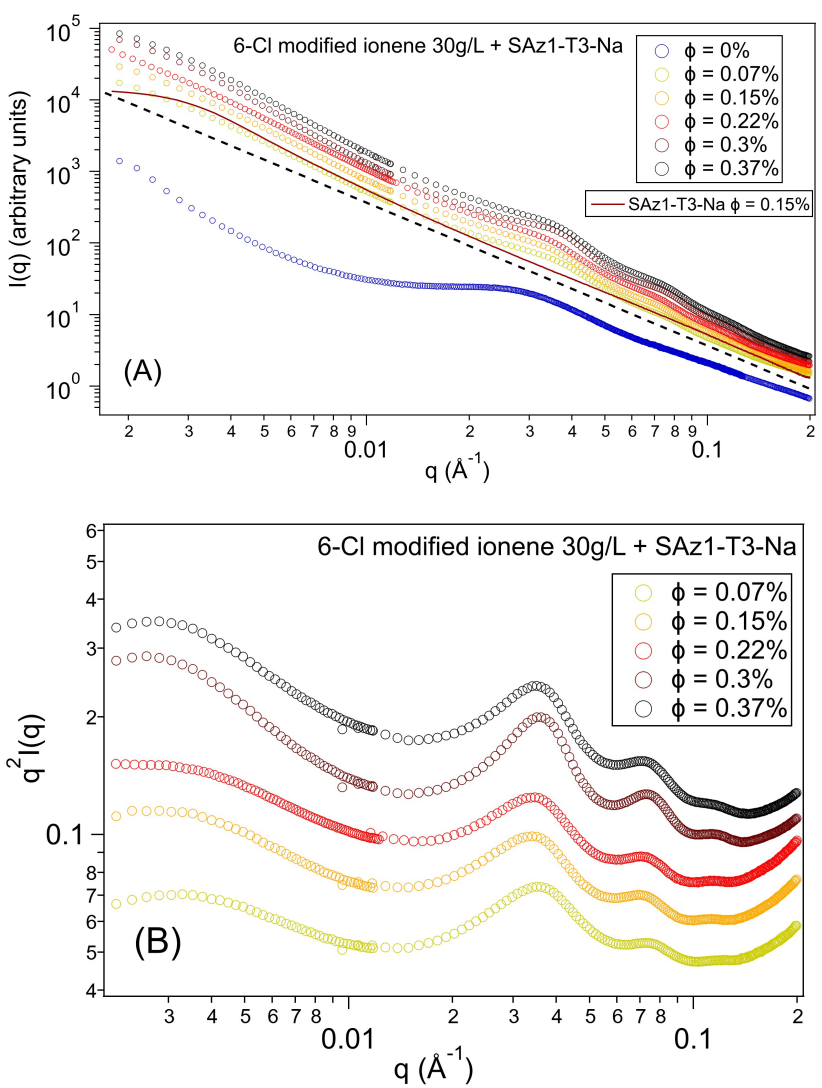

Figure 4: (A) Scattered intensity I(q) as a function of q and (B) $\mathrm{q}^{2} \mathrm{I}(\mathrm{q})$ representation of $6-\mathrm{Cl} \bmod$ ionene/SAz1-T3-Na hydrogels at a fixed ionene concentration of $30 \mathrm{~g} / \mathrm{L}$ and at different volume fractions of SAz1-T3-Na. Dashed straight line in black is a guide corresponding to $\mathrm{a} \mathrm{q}^{-2}$ dependence. SAXS signals of the 6-Cl mod ionene gel at $30 \mathrm{~g} / \mathrm{L}$ without clay and of a SAz1-T3-Na suspension at $\phi=$ $0.15 \%$ are displayed in (A) as references.

the difference of contrasts, the overall scattering profiles are the same. It appears that the typical distance $\Xi$ describing the mesh-size of the hydrogel seems to follow a dependence on $c^{-0.47}$. Regarding the distance between clay platelets, the exponent of the power law changes slightly to -0.4 . Thus the decrease of the typical interparticle distance with the increase of the ionene concentration is less important compare to the one of the mesh size of the pure hydrogel. Moreover, the average interparticle distance between platelets in the system is smaller than the mesh size in the pure hydrogel. To provide information on the conformation of the $6-\mathrm{Cl}$ mod ionene network inside the $6-\mathrm{Cl}$ mod ionene/SAz1-T3-Na gels, we have done small-angle neutron scattering (SANS) measurements under the contrast matching condition using a solvent with a $35 \%: 65 \%$ $\mathrm{H}_{2} \mathrm{O} / \mathrm{D}_{2} \mathrm{O}$ composition for montmorillonite and 38\%:62\% $\mathrm{H}_{2} \mathrm{O} / \mathrm{D}_{2} \mathrm{O}$ for beidellite (Figure S4). The characteristic distance between the $6-\mathrm{Cl}$ mod ionene chains within the 6-Cl mod ionene/SAz1-T3-Na gels is lower than the one in the 6 - $\mathrm{Cl}$ mod ionene gel for $10 \mathrm{~g} / \mathrm{L}(0.017 \mathrm{~mol} / \mathrm{L})$ in ionene. 

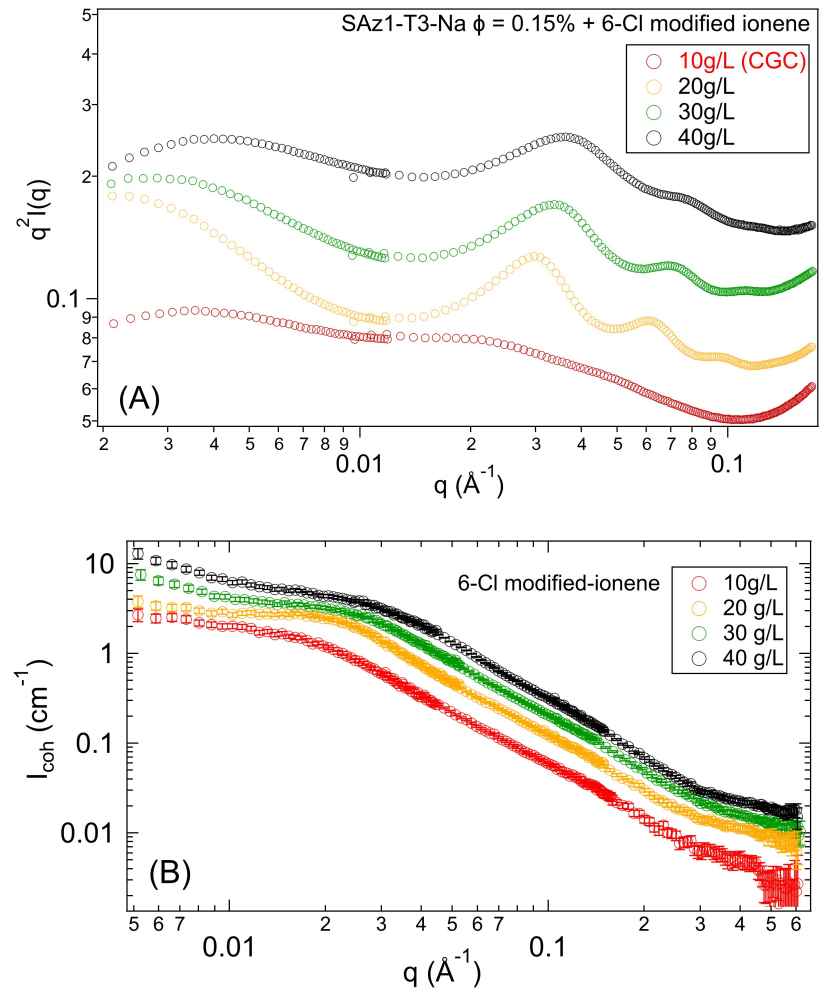

Figure 5: (A) $\mathrm{q}^{2} \mathrm{I}(\mathrm{q})$ representation of 6-Cl mod ionene/SAz1-T3-Na hydrogels at different $6-\mathrm{Cl}$ mod ionene concentrations and at a fixed volume fraction of SAz1-T3-Na $(\phi=0.15 \%)$. The curves are shifted 495 along the $\mathrm{y}$-axis for a better visualization. (B) SANS profiles of 6-Cl mod ionene pure hydrogels at different concentrations. The figure shows the coherent SANS intensity versus the wave vector $q$ of the samples in $\mathrm{D}_{2} \mathrm{O}$.

From $20 \mathrm{~g} / \mathrm{L}(0.033 \mathrm{~mol} / \mathrm{L})$, the distance between the $6-\mathrm{Cl}$ mod ionene chains within the 6 - $\mathrm{Cl}$ mod ionene/SAz1-T3$\mathrm{Na}$ gels and in the 6- $\mathrm{Cl}$ mod ionene gels is the same. Overall, only at low ionene concentration does the presence of ${ }^{505}$ clay nanoplatelets modify sligthly the final hydrogel mesh size. Thus we can suggest that the clay platelets are part of the hydrogel structure without changing its characteristic mesh size. Due to electrostatic interactions, the lateral surfaces of the clay particles are most likely covered by a layer of polyelectrolyte chains and as such inserted into $0^{510}$ the hydrogel structure.

We can also wonder if clay platelets possess such structure only in the gel or also before the gel formation, i.e. in solution at high temperature. SANS measurements of the system as a function of temperature are shown in the ${ }^{515}$ Supporting Information, Figure S5. The experiment is made in full contrast meaning that the scattering intensity results from both $6-\mathrm{Cl}$ mod ionene and the clay component. In the solution state at high temperature, before gel formation, the introduction of clay nanoplatelets leads $t^{520}$ the appearance of periodic correlation peaks with a first peak around $0.05 \AA^{-1}$. This reflects that clay platelets

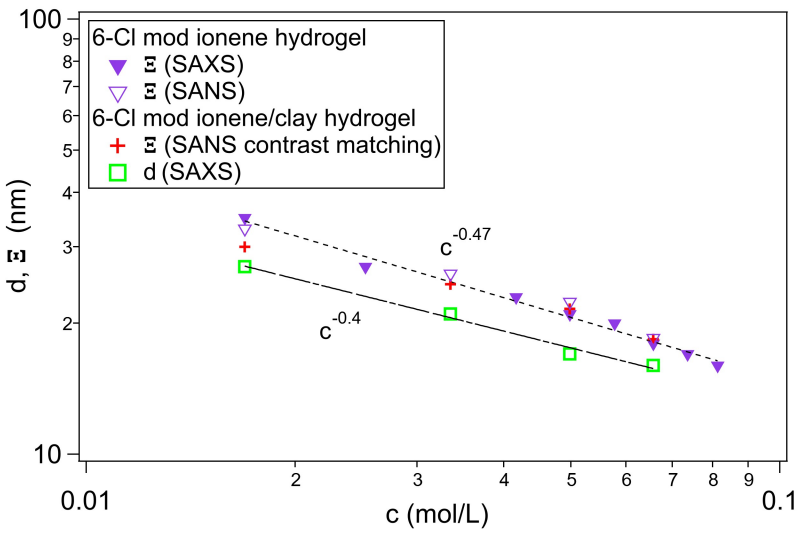

Figure 6: Evolution of the mesh size $\Xi$ of the 6 - $\mathrm{Cl}$ mod ionene chains in the pure hydrogel and in the 6- $\mathrm{Cl}$ mod ionene/clay hydrogel as a function of the $6-\mathrm{Cl} \bmod$ ionene concentration, for a fixed clay volume fraction of $\phi=0.15 \%$. Evolution of the average interparticle distance $\bar{d}$ in the 6-Cl mod ionene/clay hydrogel as a function of the 6-Cl mod ionene concentration, for a fixed clay volume fraction of $\phi$ $=0.15 \%$. Lines indicate a $c^{-0.47}$ and a $c^{-0.4}$ dependence of $\Xi$ and $\bar{d}$ respectively.

already form stacks in solution at high temperature. In the gel state, this first correlation peak appears in the low q-region around $0.035 \AA^{-1}$. The average interparticle distance changes with the gel formation as the average characteristic distance between platelets increase from $12.5 \mathrm{~nm}$ to $18 \mathrm{~nm}$ from solution to gel. Thus, when the additional mesh-size of the chain network appears on gel formation (as seen previously in Figure 2 for the 6-Cl mod ionene pure hydrogel), the face to face spacing of platelets increases. Due to electrostatic interactions, the negatively charged basal surfaces of the clay particles are already covered by the ionene chains in solution. On the formation of gel, these covered particles are inserted into the hydrogel structure.

\subsection{Influence of clay type}

The different types of smectite clays investigated here are two montmorillonites (SAz1-T3-Na and SWy2-T3-Na) and one beidellite (SBId-T3-Na). The SBId-T3-Na is a tetrahedrally substituted clay whereas the SAz1-T3-Na and the SWy2-T3-Na, are octahedrally substituted clays. It has already been shown that the charge location is a key parameter in platelet interactions 28. Indeed, the repulsive potential between individual clay platelets in suspension is sensitive to the exact location of the charge within the individual clay platelets. The tetrahedrally substituted clays are then more repulsive than the octahedrally substituted ones. In the system investigated here, the positional order of SBId-T3-Na platelets differs significantly from the one of SAz1-T3-Na and SWy2-T3-Na. At the CGC $(10 \mathrm{~g} / \mathrm{L})$, for a constant clay volume fraction of $\phi=0.15 \%$, it appears that SBId-T3-Na already displays 

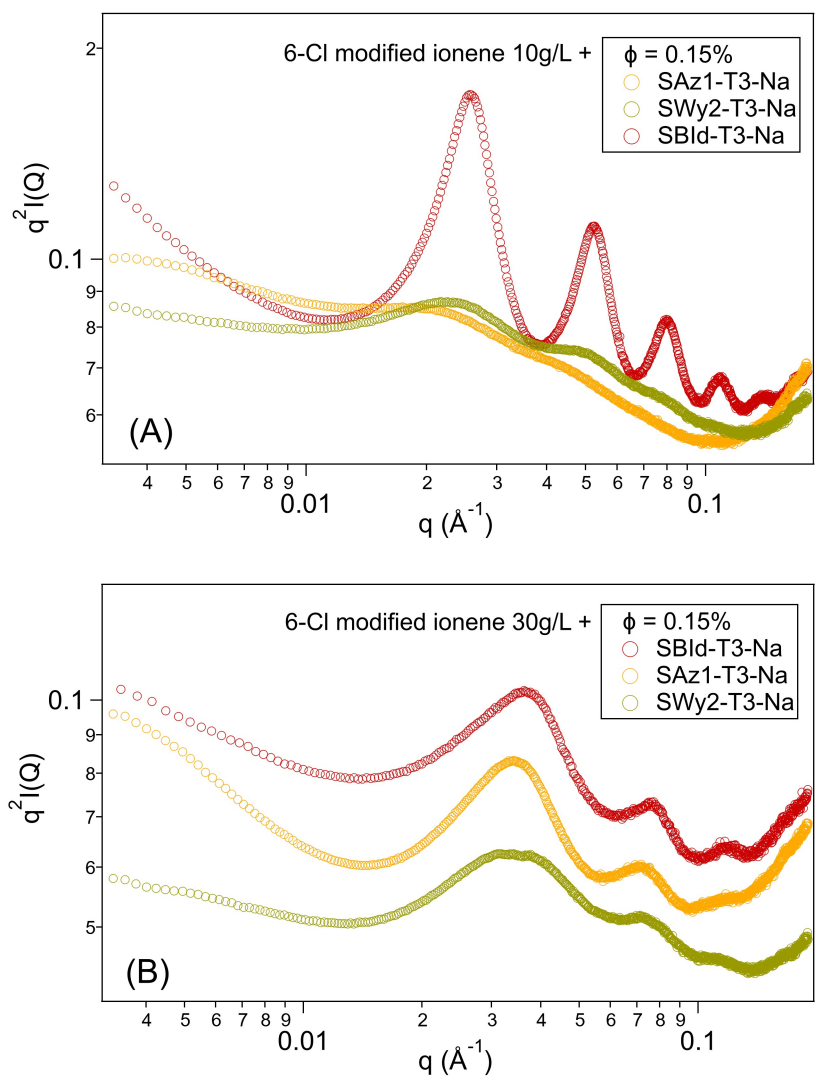

Figure 7: $\mathrm{q}^{2} \mathrm{I}(\mathrm{q})$ representation of $6-\mathrm{Cl}$ mod ionene hydrogels at $10 \mathrm{~g} / \mathrm{L}(\mathrm{A})$ and $30 \mathrm{~g} / \mathrm{L}(\mathrm{B})$ with addition of SAz1-T3-Na, SBId-T3-Na 575 and SWy2-T3-Na $(\phi=0.15 \%)$.

clearly marked periodic correlation peaks whereas with the ${ }_{580}$ SAz1-T3-Na, the pattern displays less pronounced correlation peaks as shown in Figure 7 (A). The correlation peaks of the SWy2-T3-Na are much broader than those for SBId-T3-Na. This difference could not be attributed to the difference in platelet lateral dimension be- ${ }_{585}$ tween montmorillonite and beidellite platelets as the correlation peaks do not get any sharper with the increase of the platelet lateral dimension for the scattering patterns of hydrogels with SAz1-T2-Na, SAz1-T3-Na and SAz1-T4$\mathrm{Na}$ (Supporting information, Figure S6). When the $6-\mathrm{Cl}_{590}$ mod ionene concentration is increased, the difference between the clay type is less pronounced as seen in Figure 7 (B). The structure factors of the system with beidellite and Arizona montmorillonite are then roughly the same. However, in the case of Wyoming montmorillonite, the cor- ${ }_{595}$ relation peaks are much broader. It is worth mentioning that the average interparticle distance remains the same in the system whatever the clay type for a given 6-Cl mod ionene concentration higher than the CGC. It appears also that the characteristic distance between $6-\mathrm{Cl}$ mod ionene ${ }_{600}$ chains within the 6 - $\mathrm{Cl} \bmod$ ionene/clay gels is quite the consequence, the evolution of the average interparticle distance $\bar{d}$ in the 6 -Cl mod ionene/clay hydrogel as a function of the 6 - $\mathrm{Cl}$ mod ionene concentration and for a fixed clay volume fraction of $\phi=0.15 \%$ diplayed in the Figure 6 is valid for all clay types investigated.

To better describe the structure and the difference in the sharpness of these systems, we use the Stacked Discs model 40, 41, 42, a clay platelet being assimilated to a disc, and we compare it with the scattering signal from a fully exfoliated monodisperse disc model. The scattering length density of the disc and of the water solvent, the size and the thickness of the disc are fixed parameters, with values presented in Table 1 and Table 2. The position of the correlation peak depends on the d-spacing value, so we fix it to $\frac{2 \pi}{q_{\max }}=25 \mathrm{~nm}$. We have thus simulated the scattering profile of the system using this model by varying the number of platelets per stack. We can see from Figure 8 that the number of platelets within the stacks strongly influences the sharpness of the correlation peaks. From 2 to 6 platelets per stack, the peak becomes increasingly sharper. To fit the experimental curve, we have to combine the fully exfoliated monodisperse disc model with the stacked disc model. To reproduce the scattered intensity of the first peak, a combination of stacks with a different number of platelets per stack is needed. For the $6-\mathrm{Cl}$ mod ionene hydrogel at $10 \mathrm{~g} / \mathrm{L}$ with SBId-T3-Na $(\phi$ $=0.15 \%$ ), the best simulated curve is composed of $20 \%$ of the stacked dics model with 2 platelets per stack, $10 \%$ with 3 platelets per stack, $5 \%$ with 4 platelets per stack and of $65 \%$ of the fully exfoliated monodisperse disc model as represented by the black curve in Figure 8. This means that the sharpness of the correlation peak is also reflecting the polydispersity of the system. The correlation peaks of the second and the third order are less intense than the first order peak. The simulated curve from the model presented cannot reproduce the intensity of the higher order peaks to a satisfactory level. This is partly due to the fact that clay platelets are oriented in the same direction but with a lateral disorder, as in a nematic phase.

The hydrogel with beidellite thus leads to a stronger ordering of the platelets and a higher number of platelets within a stack than the hydrogels with the two montmorillonites indicated by the sharp correlation peaks. This stronger ordering of the beidellite platelets have already been observed in clay suspensions [28. Paineau et al. 28] concluded that the repulsive interactions between the beidellite platelets are stronger than for the other types of clay, inducing a better organisation of the beidellite particles in suspension. In our system, the 6 - $\mathrm{Cl}$ mod ionene possibly interacts electrostatically more strongly with beidellite nanoplatelets than with montmorillonite. However, it is more difficult to explain the difference in the structure factors for Arizona montmorillonite and Wyoming montmorillonite because they have similar chemical formulas and the same charge location (octahedral). The difference in the broadening of the peak could not be explained just on the basis of electrostatic considerations. The possi- 


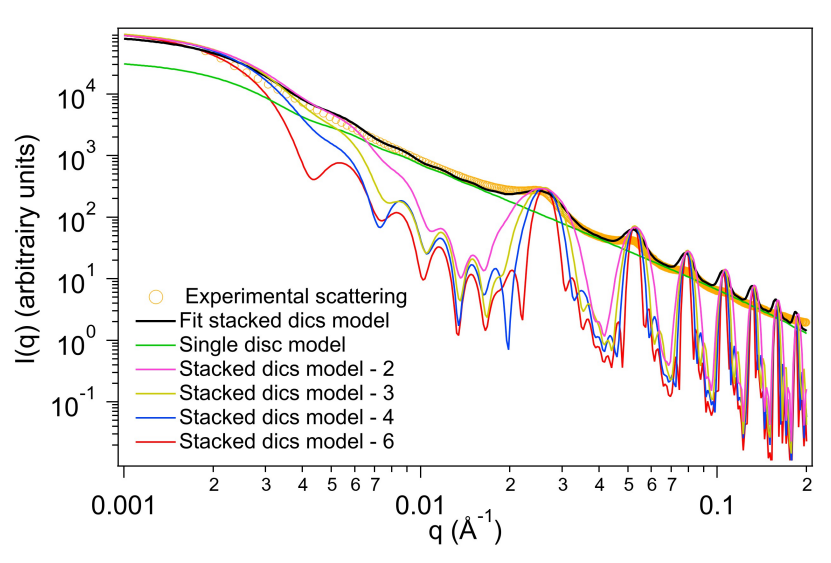

Figure 8: Scattering intensity $\mathrm{I}(\mathrm{q})$ as a function of the wave vector $\mathrm{q}$ of the 6-Cl mod ionene hydrogel at $10 \mathrm{~g} / \mathrm{L}$ with addition of SBIdT3-Na $(\phi=0.15 \%)$. The simulated curves are from the stacked disc model with different number of platelets per stack $(2,3,4$ and 6$)$ and the green curve is the simulated curve from the fully exfoliated monodisperse disc model (single disc model).

ble explanation of this phenomenon could be based on the shape of the clay platelets. Indeed, the SWy2-T3-Na could be more flexible than the SAz1-T3-Na and thus lead to a less organised system. Additional investigations would be necessary to confirm this hypothesis.

\subsection{Rheological properties}

The elastic modulus G' and the viscous modulus G" of hydrogels with clay addition is independent of the frequency and the value of $G^{\prime}$ is always a decade higher than G" as shown in Figure 9 (A). This corresponds to the behaviour of a gel. The variation of the elastic modulus G' of the hydrogels as a function of the clay volume fraction for the three different clays investigated is presented in Figure 9(B) and Figure 9 (C). Rheological measurements show that depending on the clay type, the introduction of clay nanoparticles either preserves or improves the elastic properties of the gel. Indeed, at $30 \mathrm{~g} / \mathrm{L}$ of $6-\mathrm{Cl} \mathrm{mod}$ ionene, the elastic modulus increases up to $45 \%$ of the initial value. The increase of the elastic modulus $\mathrm{G}^{\prime}$ is clearly visible for the Wyoming montmorillonite and for the beidellite whereas we do not observe a significative difference with the Arizona montmorillonite. At $10 \mathrm{~g} / \mathrm{L}$ of $6-\mathrm{Cl} \mathrm{mod}$ ionene, the elastic modulus increases much more with the addition of platelets than at $30 \mathrm{~g} / \mathrm{L}$ of ionene. Indeed, G' increases from $100 \%$ to $300 \%$ of the initial value depending on the clay type. The most important increase in $\mathrm{G}^{\prime}$ for the hydrogel is with the addition of beidellite. The lowest increase in G' stays with the addition of Arizona mont-640 morillonite. Thus, at a ionene concentration close to the gelation point, the strongest increase in G' coincides with the most organized clay structure. This suggests that the improvement of the positional order of the platelets leads to the reinforcement of the mechanical properties of the ${ }^{645}$
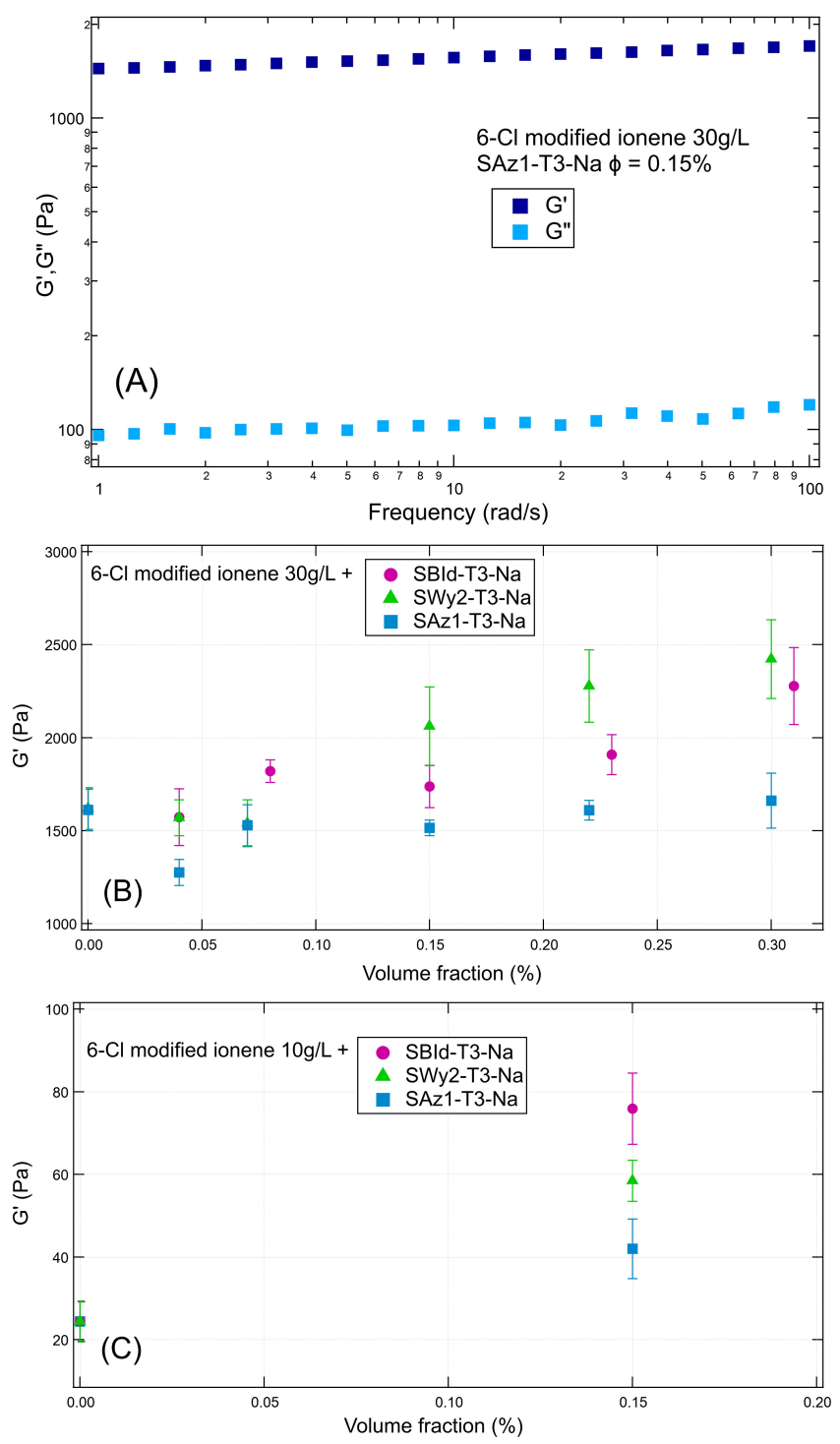

Figure 9: (A) Evolution of the elastic ( $\left.\mathrm{G}^{\prime}\right)$ and viscous (G") moduli with oscillation frequency for a $6-\mathrm{Cl} \bmod$ ionene hydrogel at $30 \mathrm{~g} / \mathrm{L}$ with SAz1-T3-Na at $\phi=0.15 \%$. The size of the symbols reflects the errors bars. (B) Evolution of the elastic modulus ( $\left.\mathrm{G}^{\prime}\right)$ as a function of clay volume fraction for a concentration of $6-\mathrm{Cl}$ mod ionene at $30 \mathrm{~g} / \mathrm{L}$. (C) Evolution of the elastic modulus (G') as a function of clay volume fraction for a concentration of $6-\mathrm{Cl} \bmod$ ionene at $10 \mathrm{~g} / \mathrm{L}$

gel. This can be explained by the possibility that the clay particles stiffen the 6-Cl mod ionene network.

\subsection{Hydrogel as a function of clay counterions}

Clay counterion exchange was performed with the SAz1T3-Na against $\mathrm{CaCl}_{2}$ and $\mathrm{La}\left(\mathrm{NO}_{3}\right)_{3}$. Whereas the SAz1T3-Na suspension, the SAz1-T3-Ca and the SAz1-T3-La in water are not exfoliated systems but form tactoids and bigger aggregates at the volume fractions investigated. The hydrogel systems containing SAz1-T3-Ca and the SAz1T3-La provide very different scattering patterns compare 

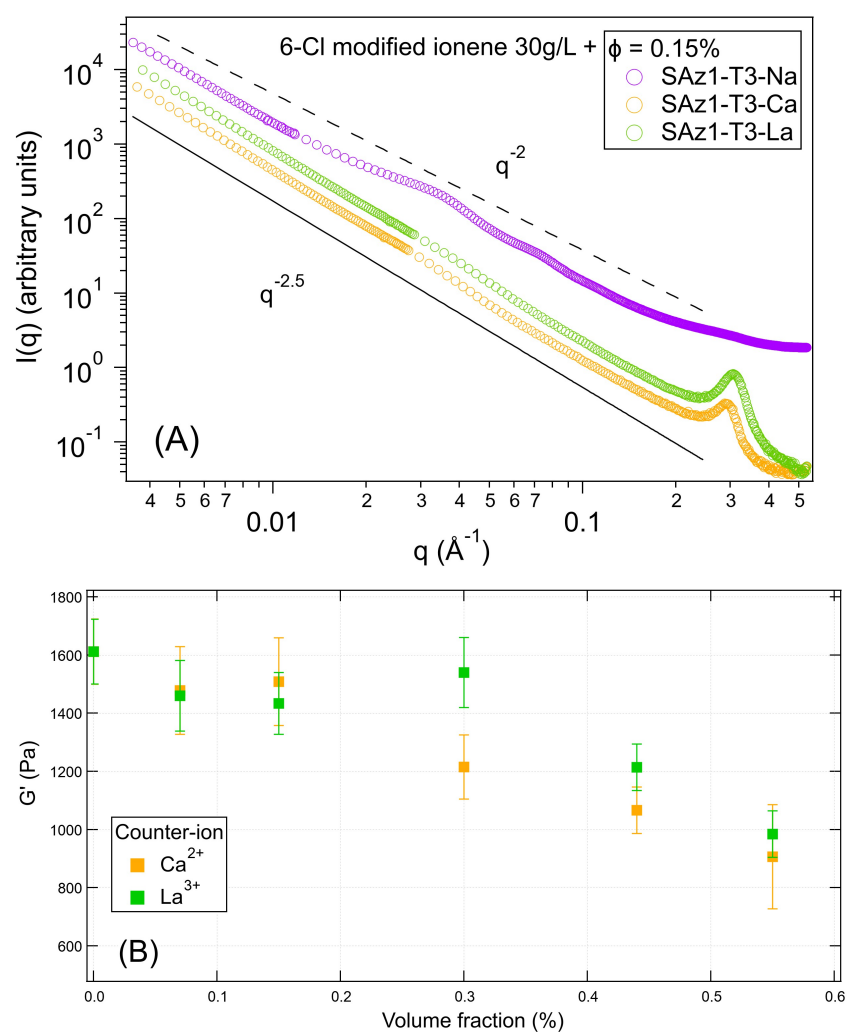

690

Figure 10: (A) Variation of the scattering intensity as a function of the wave vector $\mathrm{q}$ of the system $6-\mathrm{Cl} \bmod$ ionene/SAz1-T3 for $\mathrm{Na}^{+}$, $\mathrm{Ca}^{2+}$ and $\mathrm{La}^{3+}$ counterions $(30 \mathrm{~g} / \mathrm{L}$ of $6-\mathrm{Cl} \bmod$ ionene and $\phi=$ $0.15 \%)$. Dashed straight line in black is a guide corresponding to a $\mathrm{q}^{-2}$ dependence. Continuous line in black is a guide corresponding to a $\mathrm{q}^{-2.5}$ dependence. (B) Evolution of the elastic modulus (G') as a function of SAz1-T3 volume fraction with $\mathrm{Ca}^{2+}$ and $\mathrm{La}^{3+}$ counterions for a concentration of $6-\mathrm{Cl} \bmod$ ionene at $30 \mathrm{~g} / \mathrm{L}$.

to SAz1-T3-Na as summarized in Figure 10 (A). Indeed, ${ }^{700}$ at $30 \mathrm{~g} / \mathrm{L}$ of $6-\mathrm{Cl}$ mod ionene, the slope in the low-q region loses the $\mathrm{q}^{-2}$ dependence and the exponent increases to -2.5 for SAz1-T3-Ca and SAz1-T3-La. The periodic modulations of the scattering intensity in the middle-q region are no longer observed but a correlation peak appears in the ${ }^{705}$ high-q region. This correlation indicates clearly the presence of clay tactoids with a small interlamellar distance (1-2 $\mathrm{nm}$ at most). The position of the peak maximum corresponds to this distance within the tactoid as $\mathrm{d}=\frac{2 \pi}{q_{\max }}$ as seen previously. For both $\mathrm{La}^{3+}$ and $\mathrm{Ca}^{2+}$ counterions, the interlamellar distance is estimated around $2.1 \mathrm{~nm}$. Studies on coagulation of montmorillonite platelets by inorganic salt of $\mathrm{La}\left(\mathrm{NO}_{3}\right)_{3}$ and $\mathrm{Ca}\left(\mathrm{NO}_{3}\right)_{2}$, 43] also highlight the presence of a correlation peak corresponding to distances around $1.9 \mathrm{~nm}$. This corresponds to the formation of faceto-face stacks of layers with a repetition distance equivalent to the intercalation of three water layers. However, the slope of the curve for aggregates of montmorillonite
$\mathrm{Ca}$ and the SAz1-T3-La flocculates is much higher than in our system, around -2.8 to -3 .

As the hydrogel structure is completely different depending on the counterions, it is interesting to link these features with the corresponding rheological properties. The variation of the elastic modulus $\mathrm{G}^{\prime}$ with clay volume fraction for SAz1-T3-Ca and SAz1-T3-La is presented in Figure 10 (B). Rheological measurements show that the elastic properties of the gel are slightly weakened on addition of 675 clay platelets. Indeed, the elastic modulus decreases down to $45 \%$ of the initial value in the range of clay volume fractions investigated. However, these systems still display the behaviour of a gel. The decrease of the G' implies that the structure of the $6-\mathrm{Cl}$ mod ionene cross-linking network is Thus, the ionene network should have a lower cross-linking density.

These observations allow us to conclude that in order to improve the mechanical properties of the gel with the addi685 tion of clay particles, the osmotic swelling of clay platelets must be achieved, i.e. the presence of tactoids must be avoided.

\section{Conclusion}

We have investigated the organisation of clay nanoplatelets within a modified ionene-based hydrogel. The addition of clay into the three-dimensional network of the hydrogel involves the emergence of a face-to-face positional order of the platelets with a repeat distance of about $20 \mathrm{~nm}$. This feature is evidenced by a clear appearance of a periodic modulation of the scattered intensity. We have first shown that the structure of the clay network is dictated by the $6-\mathrm{Cl}$ mod ionene concentration. The average interparticle distance varies only with the 6 - $\mathrm{Cl}$ mod ionene concentration and is independent of the clay volume fraction. At first sight, it is surprising that this distance does not depend on the clay volume fraction. This distance does not reflect the distance between individual platelets but the one between two platelets in a stack mediated by the 6-Cl mod ionene network. We have then investigated the influence of the clay type (and thus of the clay charge location) on the structure and properties of the hydrogel. When the charge is located at the surface of the platelet as for beidellite, the 6 - $\mathrm{Cl}$ mod ionene interacts electrostatically more strongly with clay platelets and it results in a more ordered system. Further, the short-range clay stacking tendency (i.e. tactoid formation) within the gel structure can be tuned via the nature and the valency of clay-compensating cations. With $\mathrm{Ca}^{2+}$ and $\mathrm{La}^{3+}$ clay counterions, the clay platelets are inserted in the form of tactoids, with an inter-layer distance comparable to three water layers 15. This distance is the same as for clay tactoids formed in the presence of inorganic salts $\left(\mathrm{Ca}\left(\mathrm{NO}_{3}\right)_{2}\right.$ and $\left.\mathrm{La}\left(\mathrm{NO}_{3}\right)_{3}\right)$ [3.

For the case of the monovalent clay counterions and thus in the absence of tactoids, the introduction of the 
platelike clay nanoparticles into the hydrogel network enhances their mechanical performance. Moreover, the more the system is ordered, the better the mechanical properties. With multivalent counterions, the addition of clay significantly affects the mechanical performance of the hy-770 drogel. Indeed, the elastic properties of the gel are somewhat inferior on addition of clay platelets in form of tactoids. These results show that the enhancement of the mecanical properties of the hydrogel can be achieved only775 if the osmotic swelling of clay platelets occurs.

Beyond the nature of the clay counterions, the properties of the ionene based gel can be further tuned via the counterions of the polyelectrolyte chains themselves. ${ }^{780}$ Striking counterions specifics effects in aqueous solutions of classical ionene have already been observed 30. 31. The interaction between individual ionene chains depends dramatically on the nature of the counterion and the trends ${ }^{785}$ observed follow the empirical Hofmeister series [44. Thus, it may be relevant to investigate the platetelet organisation in the ionene based hydrogel with other ionene compensating counterions. A highly versatile hydrogel system is ${ }^{790}$ potentially at hand.

\section{Author contribution}

$\mathrm{CH}$ drafted the manuscript and conducted the investigation. CH, JSP, GD, TB, AC, LP, LM and NM performed experimental work. $\mathrm{CH}$, JSP, LM and NM jointly contributed to the design of the work. JSP, GD, LM and $\mathrm{NM}^{800}$ supervised the work. All the authors contributed to the manuscript revision and have approved the manuscript.

\section{Declaration of Competing Interest}

The authors declare that they have no known competing financial interests or personal relationships that could ${ }_{810}$ have appeared to influence the work reported in this paper.

\section{Acknowledgments}

The authors acknowledge the SOLEIL synchrotron for awarding the beamtime on beamline SWING. We would like also to thank the Laboratoire Léon Brillouin for awarding the beamtime on PAXY beamline and Mesut Demirelli ${ }^{820}$ for his help. We are grateful to the Institut Laue-Langevin for the beamtime allocation on fast access (DOI: 10.5291/ILLDATA.[86516]) for the contrast matching SANS measurements.

\section{Appendix A. Supplementary material}

The following are the Supplementary data to this arti- ${ }^{830}$

\section{References}

[1] Y. S. Zhang, A. Khademhosseini, Advances in engineering hydrogels, Science 356 (6337) (2017). doi:10.1126/science. aaf3627

[2] J. H. Ortony, T. Chatterjee, L. E. Garner, A. Chworos, A. Mikhailovsky, E. J. Kramer, G. C. Bazan, Self-Assembly of an Optically Active Conjugated Oligoelectrolyte, Journal of the American Chemical Society 133 (21) (2011) 8380-8387. doi:10.1021/ja202776b

[3] R. Takahashi, Z. L. Wu, M. Arifuzzaman, T. Nonoyama, T. Nakajima, T. Kurokawa, J. P. Gong, Control superstructure of rigid polyelectrolytes in oppositely charged hydrogels via programmed internal stress, Nature Communications 5 (1) (2014). doi: $10.1038 /$ ncomms5490

[4] M. F. Leong, J. K. C. Toh, C. Du, K. Narayanan, H. F. Lu, T. C. Lim, A. C. A. Wan, J. Y. Ying, Patterned prevascularised tissue constructs by assembly of polyelectrolyte hydrogel fibres, Nature Communications 4 (1) (2013). doi:10.1038/ncomms3353

[5] Q. Wang, J. L. Mynar, M. Yoshida, E. Lee, M. Lee, K. Okuro, K. Kinbara, T. Aida, High-water-content mouldable hydrogels by mixing clay and a dendritic molecular binder, Nature 463 (7279) (2010) 339-343. doi:10.1038/nature08693

[6] S. Rose, A. Prevoteau, P. Elzière, D. Hourdet, A. Marcellan, L. Leibler, Nanoparticle solutions as adhesives for gels and biological tissues, Nature 505 (7483) (2014) 382-385. doi: 10.1038/nature12806

[7] L. Z. Zhao, C. H. Zhou, J. Wang, D. S. Tong, W. H. Yu, $\mathrm{H}$. Wang, Recent advances in clay mineral-containing nanocomposite hydrogels, Soft Matter 11 (48) (2015) 9229-9246. doi: 10.1039/C5SM01277E

[8] C. C. Shen, S. Petit, C. J. Li, C. S. Li, N. Khatoon, C. H. Zhou, Interactions between smectites and polyelectrolytes, Ap(1) plied Clay Science 198 (2020) 105778. doi:10.1016/j.clay. 2020.105778

[9] F. Bergaya, G. Lagaly, Chapter 1 General Introduction: Clays, Clay Minerals, and Clay Science, in: Developments in Clay Science, Vol. 1, Elsevier, 2006, pp. 1-18. doi:10.1016/ S1572-4352(05)01001-9

[10] S. Sinha Ray, M. Okamoto, Polymer/layered silicate nanocomposites: a review from preparation to processing, Progress in

Polymer Science 28 (11) (2003) 1539-1641. doi:10.1016/j. progpolymsci.2003.08.002

[11] A.-M. Caminade, A. Beraa, R. Laurent, B. Delavaux-Nicot, M. Hajjaji, Dendrimers and hyper-branched polymers interacting with clays: fruitful associations for functional materials, Journal of Materials Chemistry A 7 (34) (2019) 19634-19650. doi:10.1039/C9TA05718H

[12] N. Yamaguchi, S. Anraku, E. Paineau, C. R. Safinya, P. Davidson, L. J. Michot, N. Miyamoto, Swelling Inhibition of Liquid Crystalline Colloidal Montmorillonite and Beidellite Clays by DNA, Scientific Reports 8 (1) (2018). doi:10.1038/ s41598-018-22386-7

[13] H. Takeno, A. Nakamura, Effects of molecular mass of polymer on mechanical properties of clay/poly (ethylene oxide) blend hydrogels, and comparison between them and clay/sodium polyacrylate blend hydrogels, Colloid and Polymer Science 297 (4) (2019) 641-649. doi:10.1007/s00396-019-04476-8

[14] H. Takeno, W. Nakamura, Structural and mechanical properties of composite hydrogels composed of clay and a polyelectrolyte prepared by mixing, Colloid and Polymer Science 291 (6) (2013) 1393-1399. doi:10.1007/s00396-012-2871-z

[15] Y. Sakhawoth, L. Michot, P. Levitz, A.-L. Rollet, J. SirieixPlenet, D. H. Merino, N. Malikova, Aggregation of Plate-like Colloids Induced by Charged Polymer Chains: Organization at the Nanometer Scale Tuned by Polymer Charge Density, Langmuir 35 (33) (2019) 10937-10946. doi:10.1021/acs.langmuir. $9 \mathrm{~b} 00939$

[16] H. Takeno, S. Nagai, Mechanical Properties and Structures of Clay-Polyelectrolyte Blend Hydrogels, Gels 4 (3) (2018) 71. doi:10.3390/gels4030071 
[17] T. Munteanu, C. M. Ninciuleanu, I. C. Gifu, B. Trica, E. Alexandrescu, A. R. Gabor, S. Preda, C. Petcu, C. L. Nistor, S. G. Nitu, R. Ianchis, The Effect of Clay Type on the Physicochemical Properties of New Hydrogel Clay Nanocomposites, in:910 M. Zoveidavianpoor (Ed.), Current Topics in the Utilization of Clay in Industrial and Medical Applications, InTech, 2018. doi:10.5772/intechopen.74478.

[18] B. Chen, J. R. G. Evans, H. C. Greenwell, P. Boulet, P. V. Coveney, A. A. Bowden, A. Whiting, A critical appraisal of 915 polymer-clay nanocomposites, Chem. Soc. Rev. 37 (3) (2008) 568-594. doi:10.1039/B702653F

[19] M. Janek, G. Lagaly, Interaction of a cationic surfactant with bentonite: a colloid chemistry study, Colloid and Polymer Science 281 (4) (2003) 293-301. doi:10.1007/s00396-002-0759-z 920

[20] A. Alemdar, V. Bütün, Interaction between a tertiary amine methacrylate based polyelectrolyte and a sodium montmorillonite dispersion and its rheological and colloidal properties: Sodium Montmorillonite Dispersion, Journal of Applied Polymer Science 95 (2) (2005) 300-306. doi:10.1002/app.21223. 925

[21] R. Noguchi, Reactions of n,n,n',n'-tetramethyl-diaminoalkanes with dihaloalkanes, Macromolecules 5 (3) (1972) 253-260.

[22] A. Strassburg, J. Petranowitsch, F. Paetzold, C. Krumm, E. Peter, M. Meuris, M. Köller, J. C. Tiller, Cross-Linking of a Hydrophilic, Antimicrobial Polycation toward a Fast-Swelling, An-930 timicrobial Superabsorber and Interpenetrating Hydrogel Networks with Long Lasting Antimicrobial Properties, ACS Ap-

口 plied Materials \& Interfaces 9 (42) (2017) 36573-36582. doi: 10.1021/acsami.7b10049

[23] T. Erdmenger, I. Perevyazko, J. Vitz, G. Pavlov, U. S. Schu-935 bert, Microwave-assisted synthesis of imidazolium ionenes and their application as humidity absorbers, Journal of Materials Chemistry 20 (18) (2010) 3583-3585. doi:10.1039/b921525e.

[24] M. P. Raskop, A. Grimm, A. Seubert, Polystyrene immobilized ionenes as novel stationary phase for ion chromatogra-940 phy, Microchimica Acta 158 (1-2) (2007) 85-94. doi:10.1007/ s00604-006-0650-6

[25] J. Bachl, D. Zanuy, D. E. López-Pérez, G. RevillaLópez, C. Cativiela, C. Alemán, D. D. Díaz, Synergistic Computational-Experimental Approach to Improve Ionene945 Polymer-Based Functional Hydrogels, Advanced Functional I. Materials 24 (31) (2014) 4893-4904. doi:10.1002/adfm. 201304230

[26] Y. Misawa, N. Koumura, H. Matsumoto, N. Tamaoki, M. Yoshida, Hydrogels Based on Surfactant-Free Ionene Polymers with N,N'-(p-Phenylene)dibenzamide Linkages, Macromolecules 41 (22) (2008) 8841-8846. doi:10.1021/ma801350k

[27] Y. Sakhawoth, L. J. Michot, P. Levitz, N. Malikova, Flocculation of Clay Colloids Induced by Model Polyelectrolytes: Effects of Relative Charge Density and Size, ChemPhysChem 18 (19) (2017) 2756-2765. doi:10.1002/cphc. 201700430

[28] E. Paineau, I. Bihannic, C. Baravian, A.-M. Philippe, P. Davidson, P. Levitz, S. S. Funari, C. Rochas, L. J. Michot, Aqueous Suspensions of Natural Swelling Clay Minerals. 1. Structure and Electrostatic Interactions, Langmuir 27 (9) (2011) 5562-5573. doi:10.1021/la2001255

[29] L. J. Michot, I. Bihannic, K. Porsch, S. Maddi, C. Baravian, J. Mougel, P. Levitz, Phase Diagrams of Wyoming NaMontmorillonite Clay. Influence of Particle Anisotropy, Langmuir 20 (25) (2004) 10829-10837. doi:10.1021/la0489108

[30] N. Malikova, S. Čebašek, V. Glenisson, D. Bhowmik, G. Carrot, V. Vlachy, Aqueous solutions of ionenes: interactions and counterion specific effects as seen by neutron scattering, Physical Chemistry Chemical Physics 14 (37) (2012) 12898-12904. doi:10.1039/c2cp41859b

900 [31] N. Malikova, A.-L. Rollet, S. Čebašek, M. Tomšič, V. Vlachy, On the crossroads of current polyelectrolyte theory and counterion-specific effects, Physical Chemistry Chemical Physics 17 (8) (2015) 5650-5658. doi:10.1039/C4CP05469E

[32] Ornstein, S. L., Zernike, F., Proc. Acad. Sci. Amsterdam 17 (1914) 795.

[33] K. Morishima, X. Li, K. Oshima, Y. Mitsukami, M. Shibayama,
Small-angle scattering study of tetra-poly(acrylic acid) gels, The Journal of Chemical Physics 149 (16) (2018) 163301. doi: $10.1063 / 1.5027665$

[34] E. Dubois, F. Boué, Conformation of Poly(styrenesulfonate) Polyions in the Presence of Multivalent Ions: Small-Angle Neutron Scattering Experiments, Macromolecules 34 (11) (2001) 3684-3697. doi:10.1021/ma000956u

[35] M. Shibayama, 14 Small Angle Neutron Scattering on Gels 50.

[36] W.-R. Chen, L. Porcar, Y. Liu, P. D. Butler, L. J. Magid, Small Angle Neutron Scattering Studies of the Counterion Effects on the Molecular Conformation and Structure of Charged G4 PAMAM Dendrimers in Aqueous Solutions, Macromolecules 40 (16) (2007) 5887-5898. doi:10.1021/ma0626564

[37] R. Borsali, R. Pecora and Grillo, I., Soft-Matter Characterization, eds springer Edition, 2008.

[38] E. Paineau, K. Antonova, C. Baravian, I. Bihannic, P. Davidson, I. Dozov, M. Impéror-Clerc, P. Levitz, A. Madsen, F. Meneau, L. J. Michot, Liquid-Crystalline Nematic Phase in Aqueous Suspensions of a Disk-Shaped Natural Beidellite Clay, The Journal of Physical Chemistry B 113 (48) (2009) 15858-15869. doi:10.1021/jp908326y

[39] L. J. Michot, I. Bihannic, S. Maddi, S. S. Funari, C. Baravian, P. Levitz, P. Davidson, Liquid-crystalline aqueous clay suspensions, Proceedings of the National Academy of Sciences 103 (44) (2006) 16101-16104. doi:10.1073/pnas.0605201103

[40] A. Guinier, G. Fournet, Small-angle scattering of x-rays, John Wiley and Sons, 1955.

[41] O. Kratky, G. Porod, J. Colloid Science 4 (1949) 35.

[42] J. Higgins, H. Benoit, Polymers and neutron scattering, Clarendon, Oxford, 1994.

[43] L. J. Michot, I. Bihannic, F. Thomas, B. S. Lartiges, Y. Waldvogel, C. Caillet, J. Thieme, S. S. Funari, P. Levitz, Coagulation of Na-Montmorillonite by Inorganic Cations at Neutral pH. A Combined Transmission X-ray Microscopy, Small Angle and Wide Angle X-ray Scattering Study, Langmuir 29 (10) (2013) 3500-3510. doi:10.1021/la400245n

[44] A. Salis, B. W. Ninham, Models and mechanisms of Hofmeister effects in electrolyte solutions, and colloid and protein systems revisited, Chem. Soc. Rev. 43 (21) (2014) 7358-7377. doi:10. 1039/C4CS00144C 